\title{
Evaluation of Tree Detection and Segmentation Algorithms in Peat Swamp Forest Based on LiDAR Point Clouds Data
}

\author{
Irlan $^{1}$, Muhammad Buce Saleh ${ }^{1 *}$, Lilik Budi Prasetyo ${ }^{2}$, Yudi Setiawan ${ }^{2}$ \\ ${ }^{1}$ Department of Forest Management, Faculty of Forestry and Environment, IPB University, Academic Ring Road, \\ Campus IPB Dramaga, Bogor, Indonesia 16680 \\ ${ }^{2}$ Department of Forest Resources Conservation and Ecotourism, Faculty of Forestry and Environment, IPB University, \\ Academic Ring Road, Campus IPB Dramaga, Bogor, Indonesia 16680
}

Received March 24, 2020/Accepted July 9, 2020

\begin{abstract}
Application of LiDAR for tree detection and tree canopy segmentation has been widely used in conifer plantation forest in temperate countries with high accuracy, however its application on tropical natural forest especially peat swamp forest hardly found. The objective of this study was evaluated algorithms of individual tree detection and canopy segmentation used LiDAR data in peat swamp forest. The algorithms included (a) Local Maxima (LM) with various variable window size combined with growing region, (b) LM with various variable window size combined with Voronoi Tessellation, (c) LMwith various fixed window size combined with growing region, (d) LM with various fixed window size combined with Voronoi Tessellation, and (e) Tree Relative Distance algorithm. The results show that algorithm with the best accuracy was the Tree Relative Distance algorithm with the highest overall F-score of 0.63 . The tree relative distance algorithm also provides the highest accuracy in determining three tree parameters which are position, height and diameter of tree canopy with a RMSE value $1.08 \mathrm{~m}, 6.45 \mathrm{~m}$, and $1.19 \mathrm{~m}$, respectively.
\end{abstract}

Keywords: Individual tree detection and segmentation, LiDAR, peat swamp forest, algorithm

*Correspondence author, email: buce.saleh@gmail.com

\section{Introduction}

Remote sensing technology has been widely used in forest measurement activities. Development of remote sensing technology allows tree detection and segmentation at individual level (Zhen et al., 2016). The use of this technology is expected to replace the field measurement method that requires large costs and longer period(Hyyppa et al., 2001). Data from estimating individual tree levels (number of trees, tree position, canopy diameter and tree height) are very useful for various purposes such as estimating stand volume (Hyyppa et al., 2001), estimating aboveground biomass (Ferraz et al., 2016) and estimating of carbon stocks (Goldbergs et al., 2018). Light Detecting and Ranging (LiDAR) is a remote sensing technology that can be used for tree detection and segmentation at the individual level -(Kaartinen et al., 2012). LiDAR sensor is designed to identify the three dimensional coordinates of an object allowing for detection and segmentation of the tree - (Lim et al., 2003). LiDAR spacecraft equipped with Global Navigation Satellite Systems (GNSS) can provide accurate location information and Inertial Measurement Unit (IMU) to measure aircraft direction (White et al., 2016).

The algorithm used to tree detection and segmentation using LiDAR have been developed and tested in several forest type. In general, tree detection and segmentation algorithms at individual level can be divided into three namely Canopy Height Model (CHM) raster-based, point cloud-based and hybrid approaches. First, the raster-based approach uses CHM data to detect and segment trees such as marker-control watershed algorithm (Ene et al., 2012), pouring (Koch et al., 2006) and local maxima (LM) algorithm with Voronoi Tessellation (Silva et al., 2016). Second, the point cloud-based approach uses normalized point cloud data for tree detection and segmentation such as the tree relative distance algorithm (Li et al., 2012) and 3D Adaptive Mean Shift algorithm (Ferraz et al., 2016). Third, the hybrid approach of CHM raster and point cloud that uses the CHM raster to detect tree tops (LM) and growing canopy areas using point cloud (Dalponte \& Coomes, 2016).

Testing for tree detection and segmentation methods using LiDAR have been widely tested and compared with the results of field measurements. In raster-based approach, tree detection and segmentation rates use the marker-control watershed algorithm in pine forests in Norway with tree detection rates reaches $46-50 \%$ (Ene et al., 2012). The pouring algorithm -(Koch et al., 2006) which has similarities with marker-control watershed successfully detecting and segmenting trees in Douglas fir and deciduous stand in 
Germany with rate of correct detected respectively of $60 \%$ and 20\%. Silva et al., (2016) used LM algorithm with Voronoi Tessellation with rate of correct detection of $82 \%$. In point cloud-based approach, Li et al., (2012) used a tree relative distance algorithm tested in California coniferous forest with rate of correct detected of $86 \%$. Dalponte \& Coomes, (2016) use the hybrid approach (CHM and point cloud) to detect tree tops and growing canopy to obtain high accuracy of tree diameter classes greater than $40 \mathrm{~cm}(>60 \%)$. High accuracy testing of these methods is performed on various forest types in subtropical areas (conifer, deciduous or mixed of both)( $\mathrm{Lu}$ et al., 2014; Kim et al., 2016). Testing of tree detection and segmentation methods in various types of forests in the tropical area, especially peat swamp forest is quite few. Forest types in the tropics have a canopy structure with different from subtropical forests. Different types of forests affect the accuracy of tree detection and segmentation using LiDAR (Zawawi et al., 2015). In addition, the selection of the proper algorithm could affect the accuracy of detection and segmentation results. The tree detection and segmentation algorithm based on local maxima depends on the window size (moving window size) in detecting local maxima. Choosing the proper window size would determine the accuracy of tree detection and tree canopy segmentation (Popescu \& Wynne, 2004). Popescu \& Wynne, (2004) offer the use of variable window size obtained from the relationship between tree height and tree crown diameter as a parameter of tree detection and segmentation. Variable window size makes the window size more flexible in detecting local maxima and will change based on tree height.

The study objective was evaluated the algorithm for tree detection and segmentation in peat swamp forest used LiDAR data. The Algotihms included (1) Local Maxima (LM) with various variable window size combined with growing region, (2) LM with various variable window size combined with Voronoi Tessellation, (3) LM with various fixed window size combined with growing region, (4) LM with various fixed window size combined with Voronoi Tessellation and (5) Tree Relatif Distance algorithm. The algorithm are evaluated based on the accuracy of tree detection and segmentation as well as the accuracy of tree parameters such as position, height and diameter of the canopy.

Data of the tree position, tree height and tree canopy diameter are useful for peat swamp forest management activities. Peat swamp forest is difficult to access, making it complicate to measure stand parameters. Successful of LiDAR in measuring peat swamp forest stands parameters will be useful for monitoring success in ecosystem restoration of peat swamp forest management activities. The use of appropriate algorithms in tree detection and segmentation can improve accuracy in determining the number of trees, tree position, crown diameter and tree height estimation. Data on the number, position, crown diameter and tree height are very useful for monitoring the restoration ecosystem of peat swamp forest activities.

\section{Methods}

Research site This research was conducted in the peatland ecosystem restoration area of PT. Rimba Makmur Utama (RMU) which was administratively located in Waringin Timur Regency, Central Kalimantan Province (Figure 1). The forest type within the study area is mainly peat swamp forest with a total area of 217,755 ha. The data processing and analysis were performed at the Spatial Modeling Laboratory, Department of Conservation of Forest and Ecotourism, Faculty of Forestry, IPB-University.

LiDAR and field tree data LiDAR and field observation data was provided by Forest 2020 project. The LiDAR data acquisition which were taken by Okron Global Data limited. Field data measurement were conducted during July-August 2018. The parameters of LiDAR acquisition can be seen in Table 1.

Field tree data measurement included tree height, tree coordinates and tree species. Determination of measurement location was conducted by placing the plot within LiDAR flying area. Three plots with dimension of $40 \mathrm{~m} \times 40 \mathrm{~m}$ were used in this research. Only tree with minimum $10 \mathrm{~cm}$ diameter were surveyed within the plots. Tree coordinates were obtained by calculating the angle using a compass and the distance using rangefinder from the identified

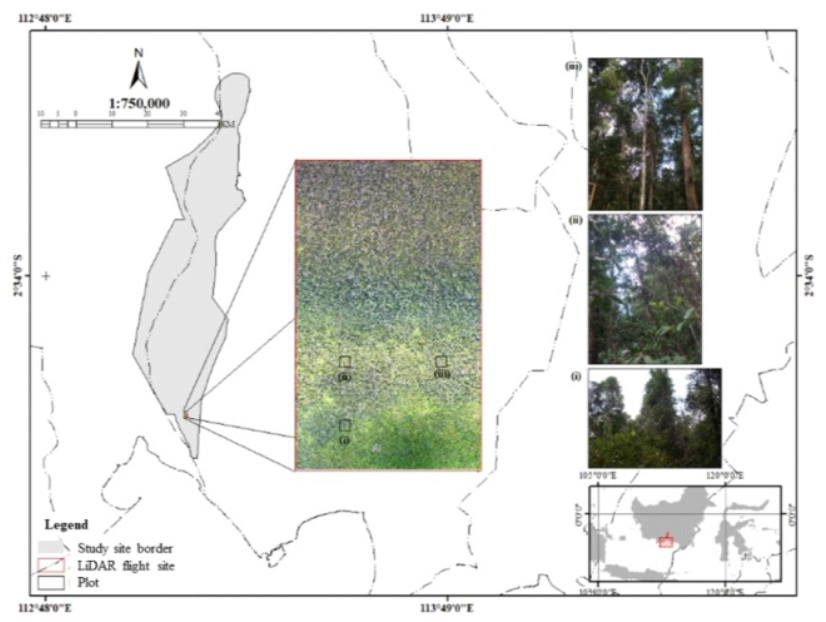

Figure 1 Research location.

Table 1 LiDAR acquisition parameter

\begin{tabular}{|c|c|}
\hline Parameter & Specification/Description \\
\hline Drone & DJI Matrice 600 \\
\hline Drone speed & $6-10 \mathrm{~m} \mathrm{~s}^{-1}$ \\
\hline Height (Flying) & $70-100 \mathrm{~m}$ above ground \\
\hline Laser speed & $2 \mathrm{~s}$ \\
\hline Horizontal accuracy & $\begin{array}{l}20-30 \mathrm{~cm} \text { using GCP and more } \\
\text { than } 1 \text { without GCP }\end{array}$ \\
\hline Vertical accuracy & $10-15 \mathrm{~cm}$ \\
\hline LiDAR density point & $12-18$ points $\mathrm{m}^{-2}$ \\
\hline Spatial resolution & $\begin{array}{l}5-15 \mathrm{~cm} \text { pixel }^{-1} \text { or depend on } \\
\text { height (flying) }\end{array}$ \\
\hline Flight sidelap & $60 \%$ \\
\hline Flight overlap & $80 \%$ \\
\hline Scaning range & $0.1-30 \mathrm{~m}$ \\
\hline Data acquisition rate & 43.200 points s ${ }^{-2}$ \\
\hline
\end{tabular}

Source: Okron Global Data (2018), Forest (2020) 
coordinates position (benchmark) whereas its position was measured by differential GPS. Tree height was measured using a hypsometer. During the survey 216 trees were measured, which was dominated by Litsea sp., Magnolia bintulensis, Cryptocarya sp., and Campnosperma coriaceum (Jack) Hallier F. Canopy diameter was obtained from the visual interpretation of orthophoto images with a spatial resolution of $5 \mathrm{~cm}$. Visual interpretation was conducted in the canopy area which had the tree coordinates of the field measurement. The diameter data from delineation results were used as the material to construct the canopy model. The canopy model would then be used as a variable window size for tree detection and segmentation using lidR package (Roussel et al., 2019).

Variable window size The fixed window size is determined by certain size of canopy diameter at the forest stand, than the variable window size used in this study was obtained from the relationship between tree canopy diameter and tree height. The selection of tree height and canopy diameter as variables was based on the assumption that there is a relationship between tree height and canopy diameter (Popescu \& Wynne, 2004). The variable window size was conducted by using 137 data of tree height and canopy diameter. Linear and non-linear regression equation models were performed to obtain the best relationship. The results of model preparation show that second order polynomial regression equation had the best relationship with $\mathrm{R}^{2} 0.53$. The equation model used as the variable window size is as shown in Equation [1].

$$
V W S=0.0033 H^{2}-0.0055 H+3.2872
$$

note: $V W S$ is variable window size or canopy sizes (meter) and $H$ is height of the tree in meter. Popescu \& Wynne, (2004) used a regression equation model for three forest types of deciduous, conifer and mixed stand with $\mathrm{R}^{2}$ values of $0.54,0.58$ and 0.59 , respectively. As a result, the detection overall accuracy reached $83 \%$. Chen et al., (2006) used a regression equation model with a value of $\mathrm{R}^{2} 0.59$ in open oak savanna forest, obtaining the highest accuracy of $64 \%$. Ma et al., (2014) used a linear regression equation with a value of $\mathrm{R}^{2}$ 0.60 in the Piceacrassifolia forest with a detection rate of $31 \%$.

Canopy height model development The generated Canopy Height Model (CHM) data often displays data pits or empty pixels that spread randomly on CHM raster that would affect estimation result (Ben-Arie et al., 2009; Khosravipour et al., 2014; Mielcarek et al., 2018). These pits had a low height compared to the surrounding area so they were considered abnormal (Zhao et al., 2013). Several pit-free CHM generating algorithms have been developed to overcome this problem. Khosravipour et al., (2014) created a pit-free CHM algorithm using normalized point cloud to build a canopy model at various layers of height which was then combined to obtain a pit-free CHM.

In this study, the CHM manufacturing algorithm used was a pit-free CHM algorithm developed by Khosravipour et al., (2014). The steps in this algorithm included: (i) Normalization of point cloud; (ii) Making partial CHM using first return at various layers of height: $0,2,5,10$ and $15 \mathrm{~m}$; (iii) Combining partial CHM raster to obtain a pit-free CHM. This algorithm would also use a sub-circle function with a radius of $25 \mathrm{~cm}$ to avoid blank pixels as well as use of the edge length parameter (max edge) Delaunay Triangulation to limit cutting of artificial interpolation. The resulting pitfree CHM raster had a resolution of $0.1 \mathrm{~m}$ due to the density of point cloud. CHM production was conducted on $\mathrm{R}$ software using the lidR package (Roussel et al., 2019)..

LiDAR tree detection and segmentation The detection and segmentation algorithms in this study included local maxima $(\mathrm{LM})+$ growing region and local maxima $(\mathrm{LM})+$ Voronoi Tessellation and Tree Relative Distance algorithm. Local maxima-based algorithm was performed using two different parameters, namely variable window size (VWS) using Equation [1] and fixed window size (FWS) with a size of 3 $\mathrm{m}$. This algorithm is available in $\mathrm{R}$ software using the lidR package

1. Local maxima (LM) + growing region algorithm

$\mathrm{LM}+$ growth region algorithm is a method that used CHM raster for local maxima detection and cloud point segmentation for canopy areas (Popescu et al., 2002; Popescu \& Wynne, 2004). Tree detection and segmentation were conducted in stages Dalponte \& Coomes, 2016) including: (i) making pit-free CHM (ii) detecting local maxima as tree tops. Pixels taken as tree tops were used as the initial area of tree canopy (seeds) to grow; (iv) canopy area segmentation using growing region algorithm based on the maximum height (th seed) percentage of local maxima detection result and percentage of growing region from average canopy area pixels (Hyyppa et al., 2001; Dalponte et al., 2015; Dalponte \& Coomes, 2016). Tree segmentation was conducted using a normalized cloud point, the cloud point would be added as a canopy area if it had more height than the tree multiplied by the specified seed threshold (th seed), and higher than average identified canopy area (th crown). The seed threshold and the growing region limit between $0-1$. This procedure was repeated for all nearby pixels, so no pixels were added to the region.

2. Local maxima and Voronoi Tessellation algorithm

This algorithm was developed by Silva et al., (2016) using a buffer method on the local maxima to grow the canopy area and Voronoi Tessellation to isolate the canopy. The segmentation process began with (i) making pit-free CHM; (ii) detecting the tree tops to be marked as local maxima (starting point of growth) as performed in the previous algorithm. (iii) Local maxima buffer was performed using a radius determined based on the relationship between the height of field tree and diameter of tree canopy (result of canopy delineation). For example, if the average canopy diameter was less than 60 percent of the average tree height, the minimum canopy factor was 0.6. (iv) The buffer results were cut using Voronoi Tessellation to isolate the tree canopy. Exception could be made for pixels with a certain height below the height of the tree (percentage) to eliminate pixels that were considered non-trees.

3. Tree relative distance algorithm 
The relative distance algorithm between trees was a point cloud-based method that used relative distance between trees to segment the tree canopy (Li et al., 2012). This algorithm assumed that there was always a distance between trees, which at the top of tree canopy had a greater distance than the lower section of tree canopy. The point cloud identification process was conducted sequentially and classified as a target tree or non-target tree. The identification process started from the tree top by entering and excluding points based on their relative distances. The taken steps in this algorithm included(Li et al., 2012): (i) Normalization of point cloud; (ii) Point cloud classification as a target tree and non-target tree. This process classified two aspects: local maxima and non-local maxima using the tree distance threshold (dt) and the minimum distance of the target tree $\left(d \min _{1}\right)$ and non-target tree $\left(\mathrm{dmin}_{2}\right)$. Determination of $\mathrm{dt}$ wad performed based on the assumption of the smallest distance between trees and dmin was determined based on the smallest diameter of canopy. Local maxima determination based on tree distance threshold was as follows: (i) if $d \min _{1}>d t$, not the target tree; (ii) if $d \min _{1} \leq$ $\mathrm{dt}$ and $d \min _{1} \leq d \min _{2}$, the target tree; (iii) if $d \min _{1} \leq \mathrm{dt}$ and $d \min _{1}>d \min _{2}$, not the target tree. Point cloud that was not local maxima (canopy area) was determined based on minimum distance rules: (i) if $d \min _{1} \leq d \min _{2}$, target tree; (ii) if $d \min _{1}>d \min _{2}$, not the target tree. The tree minimum height parameter (tree min) was also added to exclude points below the minimum tree height.

Data analysis Accuracy test was performed by comparing the estimated results from LiDAR data and field data. Accuracy tests in this study included the accuracy of tree detection and segmentation, position, height and diameter of tree canopy.

1. Tree detection and segmentation accuracy test

The evaluation of tree detection and segmentation accuracy were conducted by comparing the detection and segmentation results of the tree canopy derived from the LiDAR and tree measured from the field. The detection and segmentation of tree canopies followed the rules that included: (i) the distance from the LiDAR-based tree to the field-measured tree must be less than $60 \%$ of the average tree distance in the plot (Yao et al., 2014); (ii) the two tree canopies (LiDAR and orthophoto delineation results) shall overlap at least $20 \%$. If more than one canopy overlaped canopy of the field tree then it was selected based on the closest distance using 2D Euclidean Distance (Wallace et al., 2014). Meanwhile, the tree height criteria was not included because height tests of LiDAR and field trees would be conducted.

There were three types of tree detection and segmentation and the resulting accuracy levels were: (i) the tree was segmented correctly (true positive) if it complied with the rules mentioned earlier; (ii) the tree was not properly segmented and joined the nearest tree (false negative or omission error), (iii) the tree was missing but segmented (false positive or commission error). The three categories indicated true segmentation, under segmentation and over segmentation, respectively (Figure 2).
The evaluation of tree detection and segmentation algorithm was performed by calculating the recall, precision, and F-score of each algorithm as shown in Equation [2], Equation [3], and Equation [4] (Li et al., 2012; Lu et al., 2014; Silva et al., 2016). Recall indicated the rate of tree detected and segmented, precision indicated the rate of correct detected and segmented objects, and F-score is the overall accuracy taking both commission and omission errors into consideration that considered the error detection rate and rate of correct detected and segmented of the object using equations (Goutte \& Gaussier, 2005).

$$
\begin{array}{r}
r=\frac{T P}{T P+F N} \\
p=\frac{T P}{T P+F P} \\
F \text {-score }=2 \times \frac{r \times p}{r+p}
\end{array}
$$

note: $r=$ recall; $p=$ precision; $F=\mathrm{F}$-score; $T P=$ true positive; $F N=$ false negative; $F P=$ false positive.

Recall, precision and F-score value varied from 0 to 1 . Calculation of recall, precision and F-score values are performed using Microsoft Excel software.

2. Position accuracy, canopy diameter and tree height tests

Tree position accuracy, canopy diameter and tree height tests were used to determine the suitability of tree position, canopy diameter and tree height from LiDAR with field tree position, canopy diameter and tree height. Tree position accuracy, canopy diameter and tree height that were often used was Root Mean Square Error (RMSE) as shown in Equation [5]. This accuracy test was only performed on trees that were detected correctly (true positive - TP). Calculating of RMSE value was performed using Microsoft Excel software.

$$
\mathrm{RMSE}=\sqrt{\frac{1}{\mathrm{n}} \sum\left(\mathrm{y}_{\mathrm{i}}-\mathrm{y}\right)^{2}}
$$

note: $\mathrm{n}=$ number of trees; $\mathrm{y}_{\mathrm{i}}=$ position, canopy diameter, and height of field trees; $\grave{y}_{\mathrm{i}}=$ position, canopy diameter, and height of the LiDAR tree.

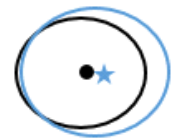

(i)

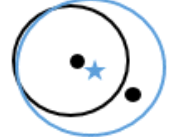

(ii)

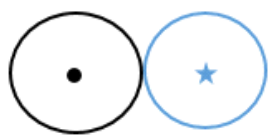

(iii)
Figure2 Three segmentation: (i) True Positive (TP); (ii) False Negatif(FN); (iii) False Positive (FP). Where the black circle indicated the tree canopy result of orthophoto delineation and the blue circle indicated the result of LiDAR tree canopy segmentation. 


\section{Results and Discussion}

Tree detection and segmentation accuracy The test results are presented in Table 2. The detection and segmentation accuracy of each algorithm has an overall F-score from 0.40 to 0.63 . The tree relative distance algorithm has the highest overall F-score of 0.63 , which indicates that this algorithm has better performance compared to other algorithms. Similar conditions are also obtained by Vega et al., (2014), a higher overall F-score is obtained from a point cloud-based algorithm compared to a raster-based algorithm. The lowest accuracy is obtained from the LM + fix window size + growing region algorithm with an overall F-score of 0.40 . Jeronimo et al., (2018) detected and segmented trees in mixed coniferous forests with F-score varying from 0.27 to 0.77 . He also indicates that many errors occur in high tree densities and have a multi-layered canopies. Forest types that have a high density or many small trees will be more difficult to detect and over-segmentation of canopy area occurs in the detected trees (Hamraz et al., 2017). Forests with high canopy cover causes low trees to be covered by higher canopy trees. While forests with high stand densities have overlapping crowns, so that make difficult to detect and segmentation. It is difficult to compare the detection accuracy and segmentation of trees from this study by previous studies due to differences in forest types and LiDAR data resolution (Zawawi et al., 2015).

What can be performed to improve the detection of LiDAR trees accuracy is to increase the resolution of LiDAR data and the development of appropriate algorithms. The results of this study provide the basis for further research related to the detection and segmentation of trees using LiDAR in peat swamp forest or other types of tropical forests. The use of point cloud-based algorithms provides promising results with the highest accuracy as indicated in this study. Errors caused in making can be avoided by using point cloud-based algorithms CHM (Li et al., 2012; Zawawi et al., 2015).

The lowest commission error is obtained from LM algorithm + variable window size + growing region with a percentage of $20 \%$ but this algorithm has the highest omission error with a percentage of $70 \%$. High omission errors value in this algorithm mostly occur by trees with a height of less than $10 \mathrm{~m}$ with a percentage of $94 \%$. These results differ from previous studies that commission errors tend to be caused by tall tree (Vega et al., 2014; Wallace et al., 2014; Jeronimo et al., 2018). The algorithm with the lowest omission error is the relative distance of trees with a percentage of $27 \%$. Trees with a height of less than $10 \mathrm{~m}$ accounted for the highest error with a percentage of $68 \%$. This result indicates that for the tree relative distance algorithm, the detection and segmentation of low trees (underestimate) occurs mostly in trees with a height class of less than $10 \mathrm{~m}$. Commission errors indicate over-estimation results and omission errors indicate under-estimation ( $\mathrm{Li}$ et al., 2012; Hamraz et al., 2017). Tree height affects the error rate in tree detection and segmentation both commission errors and omission errors (Vega et al., 2014; Wallace et al., 2014). In addition to tree height, canopy cover and tree density also affect commission error and omission errors (Jeronimo et al., 2018).

The display of detection results of tree detection and segmentation accuracy can be seen in Figure 3. The LiDAR tree canopy has a larger size than the tree canopy/reference. This result occurs to all the tree detection and segmentation

Table 2 Results of tree detection and segmentation accuracy tests on all three algorithms.

\begin{tabular}{|c|c|c|c|c|c|c|c|c|c|}
\hline $\begin{array}{l}\text { Height } \\
\text { class }(\mathrm{m})\end{array}$ & Field trees & $\begin{array}{c}\text { Estimate } \\
\text { d trees }\end{array}$ & TP & FN & FP & $r$ & $p$ & $\begin{array}{c}F- \\
\text { score }\end{array}$ & Algorithm \\
\hline$<10$ & 128 & 26 & 8 & 120 & 18 & 0.06 & 0.31 & 0.10 & \multirow{4}{*}{$\begin{array}{c}L M+V W S+ \\
\text { growing } \\
\text { region }\end{array}$} \\
\hline $10-20$ & 70 & 54 & 38 & 32 & 16 & 0.54 & 0.70 & 0.61 & \\
\hline$>20$ & 18 & 37 & 27 & 0 & 10 & 1.00 & 0.73 & 0.84 & \\
\hline Total & 216 & 117 & 73 & 152 & 44 & 0.32 & 0.62 & 0.43 & \\
\hline$<10$ & 128 & 26 & 4 & 124 & 22 & 0.04 & 0.15 & 0.06 & \multirow{4}{*}{$\begin{array}{c}L M+V W S+ \\
\text { Voronoi } \\
\text { Tessellation }\end{array}$} \\
\hline $10-20$ & 70 & 59 & 36 & 34 & 23 & 0.51 & 0.61 & 0.56 & \\
\hline$>20$ & 18 & 45 & 30 & 0 & 15 & 1.00 & 0.67 & 0.80 & \\
\hline Total & 216 & 130 & 70 & 136 & 60 & 0.34 & 0.54 & 0.42 & \\
\hline$<10$ & 128 & 29 & 8 & 120 & 21 & 0.06 & 0.28 & 0.10 & \multirow{4}{*}{$\begin{array}{c}L M+F W S+ \\
\text { growing } \\
\text { region }\end{array}$} \\
\hline $10-20$ & 70 & 83 & 38 & 0 & 45 & 1.00 & 0.46 & 0.63 & \\
\hline$>20$ & 18 & 58 & 27 & 0 & 31 & 1.00 & 0.47 & 0.64 & \\
\hline Total & 216 & 170 & 73 & 120 & 97 & 0.38 & 0.43 & 0.40 & \\
\hline$<10$ & 128 & 30 & 11 & 98 & 19 & 0.10 & 0.37 & 0.16 & \multirow{4}{*}{$\begin{array}{c}L M+F W S+ \\
\text { Voronoi } \\
\text { Tessellation }\end{array}$} \\
\hline $10-20$ & 70 & 87 & 61 & 0 & 26 & 1.00 & 0.70 & 0.82 & \\
\hline$>20$ & 18 & 69 & 43 & 0 & 26 & 1.00 & 0.62 & 0.77 & \\
\hline Total & 216 & 186 & 115 & 98 & 71 & 0.54 & 0.62 & 0.58 & \\
\hline$<10$ & 128 & 69 & 15 & 59 & 54 & 0.20 & 0.22 & 0.21 & \multirow{4}{*}{$\begin{array}{c}\text { Trees relative } \\
\text { distances }\end{array}$} \\
\hline $10-20$ & 70 & 158 & 85 & 0 & 73 & 1.00 & 0.54 & 0.70 & \\
\hline$>20$ & 18 & 79 & 69 & 0 & 10 & 1.00 & 0.87 & 0.93 & \\
\hline Total & 216 & 306 & 169 & 59 & 137 & 0.74 & 0.55 & 0.63 & \\
\hline
\end{tabular}

Note: TP: True Positive; TN: True Negative; FP: False Positive; $r$ : recall; : precision 


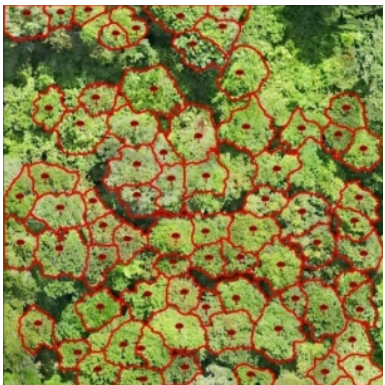

(i)

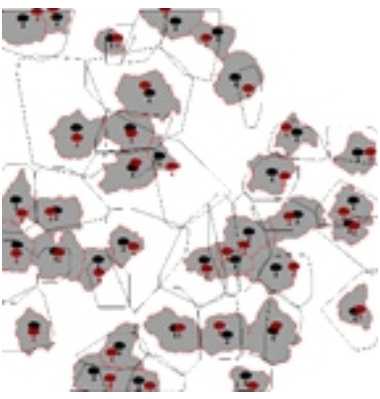

(iv)

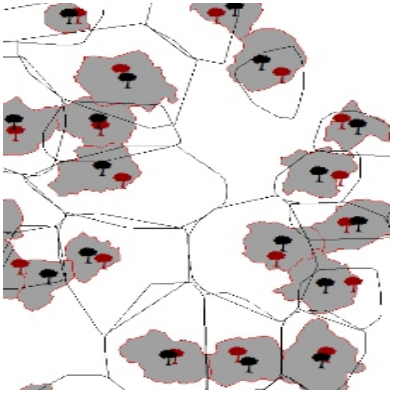

(ii)

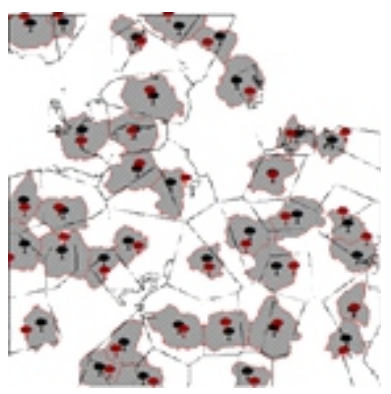

(v)

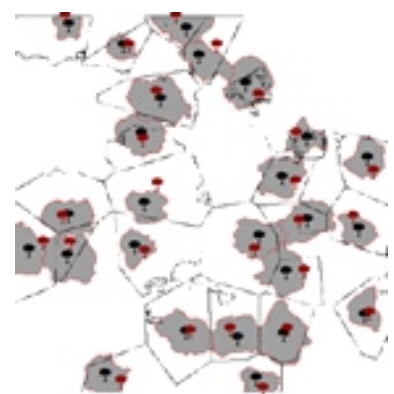

(iii)

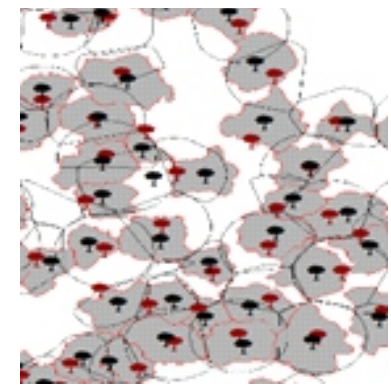

(vi)

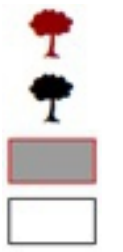

Tree of LiDAR

Tree reference

Canopy of tree reference

Canopy of LiDAR trees

Figure3 Image of detected tree and segmented appropriately: (i) tree reference displayed by orthophoto; (ii) LM + VWS + growing region; (iii) LM + VWS + Voronoi Tessellation; (iv) LM + FWS + growing region; (v) LM + FWS + Voronoi Tessellation; (vi) tree relative distance.

algorithms in this study. Level of tree detection and segmentation affect the size of LiDAR canopy. The smaller the number of trees detected, the greater the size of the projected tree canopy or vice versa.

Horizontal accuracy The accuracy of tree position (horizontal accuracy) can be seen in Table 3. These results indicate that all the algorithms obtain an RMSE value of less than $1.5 \mathrm{~m}$. The tree relative distance algorithm has the highest horizontal accuracy with a RMSE value of $1.08 \mathrm{~m}$. Andersen et al., (2006) stated horizontal accuracy in the Douglas-fir and Ponderosa pine stands with RMSE values of $0.40-0.45 \mathrm{~m}$ and $0.25-0.56 \mathrm{~m}$. Andersen et al., (2006) also indicates that the diameter of LiDAR laser pulse give an affects to the horizontal accuracy. Kaartinen et al., (2012) in his research comparing several tree detection and segmentation algorithms in mixed coniferous forests which obtain RMSE values varying from 0.50 to $2 \mathrm{~m}$. The results also indicate the effect of point cloud density on horizontal accuracy, the higher the point cloud density, the higher the horizontal accuracy. Eysn et al., (2015) in his research obtained higher horizontal accuracy in forest types with a single layer of canopy compared to forest types with more
Table 3 RMSE values of overall tree positions in each algorithm

\begin{tabular}{lc}
\hline \multicolumn{1}{c}{ Algorithm } & Overall RMSE $(\mathrm{m})$ \\
\hline$L M+$ VWS + growing region & 1.42 \\
$L M+V W S+$ Voronoi Tessellation & 1.40 \\
$L M+F W S+$ growing region & 1.16 \\
$L M+F W S+$ Voronoi Tessel lation & 1.26 \\
Trees relative distance & 1.08 \\
\hline
\end{tabular}

than one canopy layer (multilayer). The research also indicates that horizontal accuracy in conifer forests is better than mixed (heterogenous) forests.

The relationship between tree height and horizontal accuracy can be seen in Figure 4. The highest horizontal accuracy is obtained in tree height class of less than $10 \mathrm{~m}$. Different results obtained by Eysn et al., (2015), stated better horizontal accuracy at higher tree height classes.

Vertical accuracy Tree height accuracy (vertical accuracy) can be seen in Table 4 . The tree relative distance algorithm 
has the best vertical accuracy with a RMSE value of $6.45 \mathrm{~m}$. The results of this study also indicate that LiDAR tree is taller than the height of field tree. Overestimation of tree height is also obtained by Dalponte et al., (2015) who compared three methods with RMSE values varying between 1.86 and 4.14 $\mathrm{m}$ in $\mathrm{dbh}>17.5 \mathrm{~cm}$ classes. Jakubowski et al., (2013) in their research on mixed coniferous forest types stated a vertical accuracy with a RMSE value of $4.15 \mathrm{~m}$. The study also indicates that a decrease in vertical accuracy will occur in higher tree densities. The process of matching LiDAR trees and field trees can become a cause of discrepancy seen from the height difference between LiDAR trees and field trees (Morsdorf et al., 2004). It must be noted that this study does not include height parameters in the process of matching LiDAR trees and field trees.

Vertical accuracy of each tree height class can be seen in Figure 5. The highest RMSE value in the tree height class is less than $10 \mathrm{~m}$ on all algorithms. In this class, LiDAR tree has a higher height than the field tree. Meanwhile, trees with a height of more than $20 \mathrm{~m}$ have a lower RMSE value range from $5.79-7.24 \mathrm{~m}$.
Tree canopy diameter accuracy This study compared the canopy diameter results from visual analysis with the canopy diameter of LiDAR trees. The overall accuracy of tree canopy diameter can be seen in Table 5. These results indicate that the tree relative distance algorithm has the highest accuracy with a RMSE value of $1.19 \mathrm{~m}$. Canopy diameter is often ignored and not to be measured in forest inventories. Canopy diameter is obtained from estimation based on other forest parameters such as tree height for estimating above-surface biomass or canopy cover (Popescu et al., 2003; Ferraz et al., 2016).

RMSE value in each tree height class can be seen in Figure 6. The highest RMSE value in tree height class is less than $10 \mathrm{~m}$ with a range of 1.53-3.91 $\mathrm{m}$. In this class, tree detection and segmentation results generally have a larger canopy diameter compared to field trees. Meanwhile, trees with a height of more than $20 \mathrm{~m}$ have a lower RMSE value range from $1.38-1.97$.

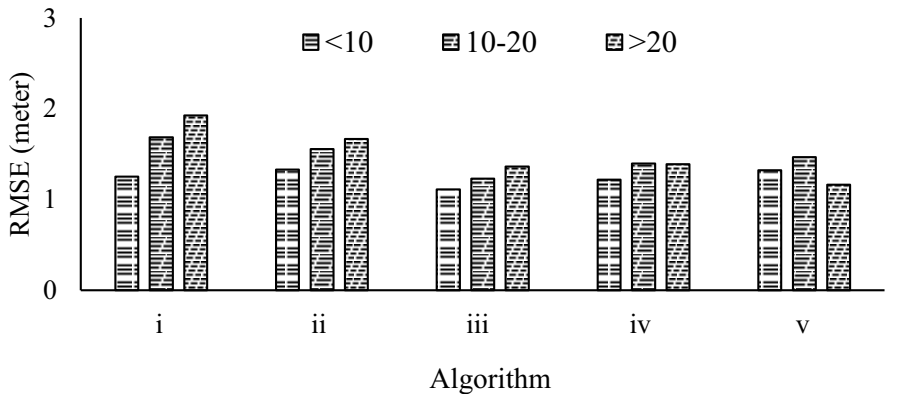

Figure 4 RMSE value of tree position $(m)$ in each algorithm: (i) $\mathrm{LM}+\mathrm{VWS}+$ growing region; (ii) $\mathrm{LM}+\mathrm{VWS}+$ Voronoi Tessellation; (iii) LM + FWS + growing region; (iv) LM + FWS + Voronoi Tessellation; (v) tree relative distance.

Table 4 RMSE values of overall tree height in each algorithm

\begin{tabular}{lr}
\hline \multicolumn{1}{c}{ Algorithm } & Overall RMSE $(\mathrm{m})$ \\
\hline$L M+V W S+$ growing region & 8.46 \\
$L M+V W S+$ Vor onoi Tessel lation & 9.51 \\
$L M+F W S+$ growing region & 8.65 \\
$L M+F W S+$ Voronoi Tessel lation & 9.11 \\
Tree relative distance & 6.45 \\
\hline
\end{tabular}

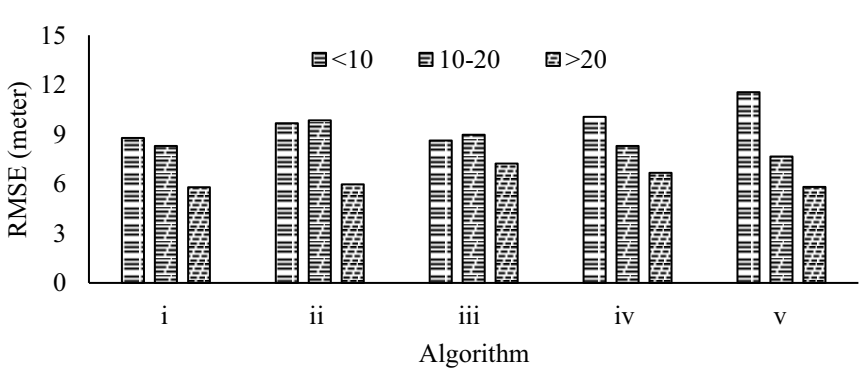

Figure 5 RMSE value of tree height ( $\mathrm{m}$ ) in each algorithm: (i) $\mathrm{LM}+\mathrm{VWS}+$ growing region; (ii) LM + VWS + Voronoi Tessellation; (iii) LM + FWS + growing region; (iv) LM + FWS + Voronoi Tessellation; (v) tree relative distance.

Table 5 Overall RMSE values of canopy diameter in each algorithm

\begin{tabular}{lr}
\hline \multicolumn{1}{c}{ Algorithm } & Overall RMSE (m) \\
\hline$L M+V W S+$ growing region & 3.47 \\
$L M+V W S+$ Voronoi Tessel lation & 2.67 \\
$L M+F W S+$ growing region & 2.86 \\
$L M+F W S+$ Voronoi Tessel lation & 1.66 \\
Tree relative distance & 1.19 \\
\hline
\end{tabular}




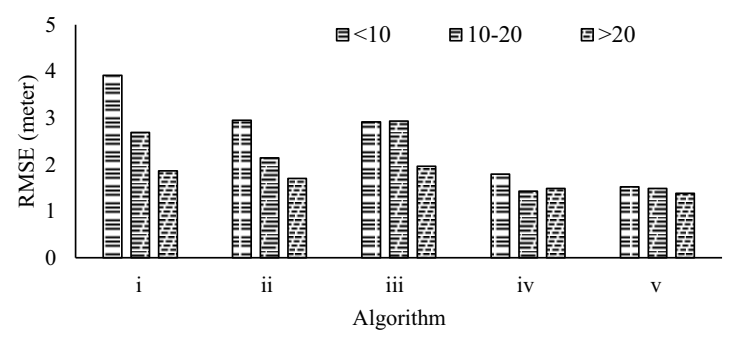

Figure 6 RMSE (m) tree height for each algorithm: (i) LM + VWS + growing region; (ii) LM + VWS + Voronoi Tessellation; (iii) LM + FWS + growing region; (iv) LM + FWS + Voronoi Tessellation; (v) tree relative distance

\section{Conclusion}

This research concludes that the tree detection and segmentation algorithm with the best accuracy was the tree relative distance algorithm with the highest F-score of 0.63 . The lowest commission error obtained from the LM + VWS + growing region algorithm with a percentage of $20 \%$ but this algorithm has the highest omission error with a percentage of $70 \%$. The algorithm with the lowest omission error was the relative distance of trees with a percentage of $27 \%$. Trees with a height of less than $10 \mathrm{~m}$ accounted for the highest error with a percentage of $68 \%$. The Tree Relative Distance algorithm also provides the highest accuracy in determining three tree parameters namely position, height and diameter of tree canopy with a RMSE value each of $1.08 \mathrm{~m}, 6.45 \mathrm{~m}$ and $1.19 \mathrm{~m}$.. The result of this study provides the basis for further research in tree detection and segmentation using LiDAR, especially in peat swamp forest or other types of tropical forests. Further, development and testing of point cloudbased algorithms need to be performed because they provide promising result with the highest accuracy. Finally, errors in making CHM can be avoided by using point cloud-based algorithms.

\section{Acknowledgment}

We would like to express our gratitude towards the International Partnership Programme (IPP) of the UK Space Agency through Ecometrica under Forests 2020 Project (https://ecometrica.com/forests2020) for the financial assistance.

\section{References}

Andersen, H. E., Reutebuch, S. E., \& McGaughey, R. J. (2006). A rigorous assessment of tree height measurements obtained using airborne LiDAR and conventional field methods. Canadian Journal of Remote Sensing, 32, 355-366. https://doi.org/10.5589/ $\mathrm{m} 06-030$

Ben-Arie, J. R., Hay, G. J., Powers, R. P., Castilla, G., \& StOnge, B. (2009). Development of a pit filling algorithm for LiDAR canopy height models. Computers Geosciences, 35, 1940-1949. https://doi.org/10.1016/ j.cageo.2009.02.003
Chen, Q., Baldocchi, D., Gong, P., \& Kelly, M. (2006). Isolating individual trees in a savanna woodland using small footprint lidar data. Photogrammetric Engineering Remote Sensing, 72, 923-932. https://doi.org/10.14358/ PERS.72.8.923

Dalponte, M., \& Coomes, D. A. (2016). Tree centric mapping of forest carbon density from airborne laser scanning and hyperspectral data. Methods in Ecology, 7, 1236-1245. https://doi.org/10.1111/2041-210X.12575

Dalponte, M., Reyes, F., Kandare, K., \& Gianelle, D. (2015). Delineation of individual tree crowns from ALS and hyperspectral data: A comparison among four methods. European Journal of Remote Sensing, 48, 365-382. https://doi.org/10.5721/EuJRS20154821

Ene, L., Næsset, E., \& Gobakken, T. (2012). Single tree detection in heterogeneous boreal forests using airborne laser scanning and area-based stem number estimates. International Journal of Remote Sensing, 33, 5171-5193. https://doi.org/10.1080/01431161. 2012.657363

Eysn, L., Hollaus, M., Lindberg, E., Berger, F., Monnet, J.M., Dalponte, M., Kobal, M., Pellegrini, M., Lingua, E., \& Mongus, D. (2015). A benchmark of LiDAR-based single tree detection methods using heterogeneous forest data from the alpine space. Forests, 6, 1721-1747.

Ferraz, A., Saatchi, S., Mallet, C., \& Meyer, V. (2016). LiDAR detection of individual tree size in tropical forests. Remote Sensing of Environment, 183, 318-333. https://doi.org/10.1016/j.rse.2016.05.028

Goldbergs, G., Levick, S. R., Lawes, M., \& Edwards, A. (2018). Hierarchical integration of individual tree and area-based approaches for savanna biomass uncertainty estimation from airborne LiDAR. Remote Sensing and Environment, 205, 141-150. https://doi.org/ 10.1016/j.rse.2017.11.010

Goutte C., \& Gaussier E. (2005). A Probabilistic Interpretation of Precision, Recall and F-Score, with Implication for Evaluation. In: Losada D.E., FernándezLuna J.M. (eds) Advances in Information Retrieval (pp. 345-359). ECIR 2005. Lecture Notes in Computer Science, vol 3408. Springer, Berlin, Heidelberg. https://doi.org/10.1007/978-3-540-31865-1_25

Hamraz, H., Contreras, M. A., \& Zhang, J. (2017). Vertical stratification of forest canopy for segmentation of understory trees within small-footprint airborne LiDAR point clouds. ISPRS Journal of Photogrammetry and Remote Sensing, 130, 385-392. https://doi.org/10.1016/ j.isprsjprs.2017.07.001

Hyyppa, J., Kelle, O., Lehikoinen, M., \& Inkinen, M. (2001). A segmentation-based method to retrieve stem volume estimates from 3-D tree height models produced by laser scanners. IEEE Transactions on Geoscience Remote Sensing, 39, 969-975. https://doi.org/10.1109/ 


\subsection{4}

Jakubowski, M. K., Li, W., Guo, Q., \& Kelly, M. (2013). Delineating individual trees from LiDAR data: a comparison of vector-and raster-based segmentation approaches. Remote Sensing, 5, 4163-4186. https://doi.org/10.3390/rs5094163

Jeronimo, S. M., Kane, V. R., Churchill, D. J., McGaughey, R. J., \& Franklin, J. F. (2018). Applying LiDAR individual tree detection to management of structurally diverse forest landscapes. Journal of Forestry, 116, $336-346$

Kaartinen, H., Hyyppä, J., Yu, X., Vastaranta, M., Hyyppä, H., Kukko, A., ..., \& Wu, J-C. (2012). An international comparison of individual tree detection and extraction using airborne laser scanning. Remote Sensing, 4(4), 950-974. https://doi.org/10.3390/rs4040950

Khosravipour, A., Skidmore, A. K., Isenburg, M., Wang, T., \& Hussin, Y. A. (2014). Generating pit-free canopy height models from airborne lidar. Photogrammetric Engineering Remote Sensing, 80, 863-872. https://doi. org/10.14358/PERS.80.9.863

Kim, E., Woo-Kyun, L., Yoon, M., Lee, J.-Y., Lee, E. J., \& Moon, J. (2016). Detecting individual tree position and height using Airborne LiDAR data in Chollipo Arboretum, South Korea. TAO: Terrestrial, Atmospheric Oceanic Sciences, 27, 593-604. https://doi.org/10.3319/ TAO.2016.03.29.01(ISRS)

Koch, B., Heyder, U., \& Weinacker, H. (2006). Detection of individual tree crowns in airborne LiDAR data. Photogrammetric Engineering Remote Sensing, 72, 357-363. https://doi.org/10.14358/PERS.72.4.357

Li, W., Guo, Q., Jakubowski, M. K., \& Kelly, M. (2012). A new method for segmenting individual trees from the LiDAR point cloud. Photogrammetric Engineering Remote Sensing, 78, 75-84. https://doi.org/10.14358/ PERS.78.1.75

Lim, K., Treitz, P., Wulder, M., St-Onge, B., \& Flood, M. (2003). LiDAR remote sensing of forest structure. Progress in Physical Geography: Earth and Environment, 27, 88-106. https://doi.org/10.1191/ 0309133303pp360ra

Lu, X., Guo, Q., Li, W., \& Flanagan, J. (2014). A bottom-up approach to segment individual deciduous trees using leaf-off lidar point cloud data. ISPRS Journal of Photogrammetry and Remote Sensing, 94, 1-12. https://doi.org/10.1016/j.isprsjprs.2014.03.014

Ma, H., Song, J., Wang, J., Xiao, Z., \& Fu, Z. (2014). Improvement of spatially continuous forest LAI retrieval by integration of discrete airborne LiDAR and remote sensing multi-angle optical data. Agricultural and Forest Meteorology, 189190, 60-70. https://doi.org/10.1016/ j.agrformet.2014.01.009
Mielcarek, M., Stereńczak, K., \& Khosravipour, A. (2018). Testing and evaluating different LiDAR-derived canopy height model generation methods for tree height estimation. International Journal of Applied Earth Observation Geoinformation, 71, 132-143. https://doi. org/10.1016/j.jag.2018.05.002

Morsdorf, F., Meier, E., Kötz, B., Itten, K. I., Dobbertin, M., \& Allgöwer, B. (2004). LiDAR-based geometric reconstruction of boreal type forest stands at single tree level for forest and wildland fire management. Remote Sensing of Environment, 92, 353-362. https://doi.org/ $10.1016 /$ j.rse.2004.05.013

Popescu, S. C., \& Wynne, R. H. (2004). Seeing the trees in the forest. Photogrammetric Engineering \& Remote Sensing, 70, 589-604. https://doi.org/10.14358/ PERS.70.5.589

Popescu, S. C., Wynne, R. H., \& Nelson, R. F. (2002). Estimating plot-level tree heights with lidar: Local filtering with a canopy-height based variable window size. Computers and Electronics in Agriculture, 37, 71-95.https://doi.org/10.1016/S0168-1699(02)00121-7

Popescu, S. C., Wynne, R. H., \& Nelson, R. F. (2003). Measuring individual tree crown diameter with lidar and assessing its influence on estimating forest volume and biomass. Canadian Journal of Remote Sensing, 29, 564-577. https://doi.org/10.5589/m03-027

Roussel, J.-R., Auty, D., Boissieu, F. D., \& Meador, A. S. (2019). LidR: Airborne LiDAR data manipulation and visualization for forestry applications.

Silva, C. A., Hudak, A. T., Vierling, L. A., Loudermilk, E. L., O'Brien, J. J., Hiers, J. K., ..., \& Khosravipour, A. (2016). Imputation of individual longleaf pine (Pinus palustris Mill.) tree attributes from field and LiDAR data. Canadian Journal of Remote Sensing, 42, 554-573. https://doi.org/10.1080/07038992.2016.1196582

Vega, C., Hamrouni, A., El Mokhtari, S., Morel, J., Bock, J., Renaud, J. P., ..., \& Durrieu, S. (2014). PTrees: A pointbased approach to forest tree extraction from lidar data. International Journal of Applied Earth Observation and Geoinformation, 33, 98-108. https://doi.org/10.1016/ j.jag.2014.05.001

Wallace, L., Lucieer, A., Watson, C. S. J. I. T. o. G., \& Sensing, R. (2014). Evaluating tree detection and segmentation routines on very high resolution UAV LiDAR data. IEEE Transactions on Geoscience and Remote Sensing, 52, 7619-7628. https://doi.org/10. 1109/TGRS.2014.2315649

White, J. C., Coops, N. C., Wulder, M. A., Vastaranta, M., Hilker, T., \& Tompalski, P. (2016). Remote sensing technologies for enhancing forest inventories: a review. Canadian Journal of Remote Sensing, 42, 619-641. https://doi.org/10.1080/07038992.2016.1207484 
Yao, W., Krull, J., Krzystek, P., \& Heurich, M. (2014). Sensitivity analysis of 3D individual tree detection from LiDAR point clouds of temperate forests. Forests, 5, 1122-1142.https://doi.org/10.3390/f5061122

Zawawi, A. A., Shiba, M., \& Jemali, N. J. N. (2015). Accuracy of LiDAR-based tree height estimation and crown recognition in a subtropical evergreen broadleaved forest in Okinawa, Japan. Forest systems, 24, 1-11. https://doi.org/10.5424/fs/2015241-05476
Zhao, D., Pang, Y., Li, Z., \& Sun, G. (2013). Filling invalid values in a LiDAR-derived canopy height model with morphological crown control. International Journal of Remote Sensing, 34, 4636-4654. https://doi.org/ $10.1080 / 01431161.2013 .779398$

Zhen, Z., Quackenbush, L. J., \& Zhang, L. (2016). Trends in automatic individual tree crown detection and delineation-Evolution of LiDAR data. Remote Sensing, 8, 1-26. https://doi.org/10.3390/rs8040333 